\title{
Effects of crystalline morphologies on the mechanical properties of carbon fiber reinforcing polymerized cyclic butylene terephthalate composites
}

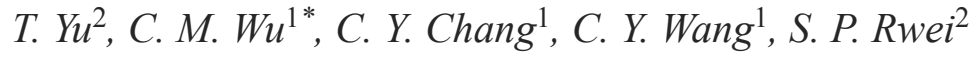 \\ ${ }^{1}$ Department of Fiber and Composite Materials, Feng Chia University, 100, Wenhwa Rd., Taichung, Taiwan 40724, \\ Republic of China \\ ${ }^{2}$ Department of Molecular Science and Engineering, National Taipei University of Technology, No. 1, Section 3, \\ Chung-Hsiao East Road, Taipei, Taiwan 10608, Republic of China
}

Received 17 August 2011; accepted in revised form 9 November 2011

\begin{abstract}
Carbon/polymerized cyclic butylene terephthalate (pCBT) composites were prepared through a modified film stacking technique. Three crystalline morphologies of carbon/pCBT composites were obtained at different crystallization temperatures. Tensile, flexural, short beam shear and impact tests were conducted. The low crystallinity carbon/pCBT samples were crystallized at $185^{\circ} \mathrm{C}$ with spherulitic structure which leads to form the large area spherulite/transcrystalline boundary regions. Consequently, the crack initiated and propagated along with 'weak' spherulite/transcrystalline boundary regions, which were resulted low mechanical properties. Carbon/pCBT sample crystallized at $210^{\circ} \mathrm{C}$ with high crystallinity and highly disordered spherulitic crystallites without spherulite/transcrystalline boundary lines or boundary crystals exhibits the highest mechanical properties.
\end{abstract}

Keywords: mechanical properties, processing technologies, polymer composites, cyclic butylenes terephthalate, spherulite boundary

\section{Introduction}

Low viscosity cyclic butylene terephthalate (CBT) oligomer is a very promising material for a new generation of thermoplastic and composite applications. CBT easily polymerizes in $3-5 \mathrm{~min}$ at $190^{\circ} \mathrm{C}$ to linear high molecular weight poly (butylene terephthalate) (pCBT) in the presence of tin or titanium catalysts $[1,2]$. Recent interest in CBT has not only prompted recycling in an attempt to manage the growing polymer waste problem, but also stimulated the research and development of thermoplastic composites.

CBT possesses important characteristics that are advantageous when processing thermoplastic composites: a water-like, low viscosity; the ability to rapidly polymerize into $\mathrm{pCBT}$ which is transformed from cyclic oligomer into linear, high-molecular weight, engineering thermoplastic; and a polymerization process that is free from low-molecular weight byproducts [3]. Because of the low viscosity characteristic, production techniques typically associated with thermoset composites, such as resin transfer molding (RTM), can be used with minor adaptations to process thermoplastic composites.

CBT polymerization can be performed above and below the melting temperature of the resulting $\mathrm{pCBT}\left(\sim 225^{\circ} \mathrm{C}\right)$. The outcome of $\mathrm{pCBT}$ is practically the same: number average molecular weight varies between 30 and $40 \mathrm{~kg} / \mathrm{mol}$, and the polydispersity index remains at approximately 2 . The remaining 
oligomer content in the pCBT sample is equivalent to the equilibrium oligomer content in $\mathrm{PBT}$, which is known to be 3-5\%. Mohd Ishak et al. [4] studied the rheological properties of pCBT and find a drastic reduction of time to complete polymerization when the polymerization temperature is above $200^{\circ} \mathrm{C}$. Researchers published differential scanning calorimetry (DSC) studies on the polymerization of CBT as well as studies about the crystallization and melting behavior of the resulting pCBT [4-9]. Tripathy et al. [10] studied the polymerization of CBT using different catalysts and discovered that the selected catalyst strongly influences the polymer conversion and the time required for polymerization. A fast catalyst such as stannoxane can complete CBT polymerization within $2-3 \mathrm{~min}$ at $190^{\circ} \mathrm{C}$, whereas a slow catalyst system like tetrakis-(2-ethylhexyl) titanate required more than 15 min [10]. Different type of catalysts have also significant influence on the molecular weight and therefore on the mechanical properties of the resulted polymer. Investigators regard the polymerization of CBT to be an athermal process because it is an entropically driven, ring-expansion polymerization [6].

Hakmé et al. [11] studied the polymerization and crystallization kinetics of CBT through dielectric sensing. They found that the simultaneous polymerization and crystallization (type I) occurred at below $200^{\circ} \mathrm{C}$; polymerization followed by crystallization (type II) at above $200^{\circ} \mathrm{C}$; and only polymerization (type III) occurred at above $220^{\circ} \mathrm{C}$. That is, the crystallization behavior of pCBT was not only affected by the crystallization condition, but also influenced by the polymerization condition. The crystal structure of $\mathrm{pCBT}$ is considered to be that same as that of PBT [12]. In contrast to the PBT, however, the lamellae in the pCBT samples are nicely defined, thicker, and well oriented. Additionally, the transition from crystalline to amorphous is more pronounced in the pCBT samples, which might be an indication of a reduction in tie molecules [13]. Our previous study $[14,15]$ on the isothermal crystallization of pCBT polymerized at $230^{\circ} \mathrm{C}$ catalogues four morphologic features: usual negative spherulites; unusual spherulites; mixed type birefringence spherulites coexisting with boundary crystals; and highly disordered spherulitic crystals corresponding to the crystallization temperatures. Thus, it can be seen visually that the processing condition like temperature strongly affects the crystal morphology, and perhaps even the final properties of the polymer and its composites.

As for the application of CBT for continuous fiberreinforced composites, there are some published works on this subject. Parton and Verpoest et al. [3, 12] studied unidirectional glass fiber reinforced pCBT composites using resin transfer molding (RTM) technique. They found that the polymerized CBT was much more brittle than normal PBT due to large and perfect crystals growth, when pCBT has been processed under isothermal RTM processing conditions (polymerization category of type I) $[12,16]$. The matrix brittleness weakens the matrix and lowers the transverse strength of the unidirectional composite.

In order to solve this problem, researchers have tried various techniques such as copolymerized CBT with $\varepsilon$-caprolactone [17], polycaprolactone (PCL) $[15,18]$ or polyvinylbutyral [19] blended with organosilicate [8], silica [20] or carbon nanotubes [21-23]. Baets et al. [18, 24] reported that the copolymerization of $\mathrm{pCBT} / \mathrm{PCL}$ hindered the crystallization of $\mathrm{pCBT}$. The $\mathrm{pCBT} / \mathrm{PCL}$ copolymer creates a much tougher material, whether it is unfilled or a glass fiber reinforced composite.

Mohd Ishak et al. [16] prepared woven glass fabric reinforced pCBT composites using a compression mold technique. The results showed that low viscosity CBT facilitates the penetration of the resin through the fabric and also exhibits strong interfacial properties. Mäder et al. [25] investigated the interphase between glass fibers and $\mathrm{pCBT}$ resins and found that the interfacial bond strength of glass/pCBT composites varied depending on the sizing formulation and properties. A non-isothermal method prepared basalt fiber reinforced $\mathrm{pCBT}$ composites was reported [26] and the results found that a fast cooling process led to less perfect crystals in the $\mathrm{pCBT}$ matrix and toughened the $\mathrm{pCBT}$ composites.

So far glass [3, 16, 18, 24-26], basalt [27] and carbon [28-30] fibers have been used as reinforcement in $\mathrm{pCBT}$ composites and evaluated its reinforcing effects by many researcher. However, effects of crystalline morphology on the mechanical properties of the carbon/pCBT composites have not been yet examined. Therefore, we are interested in investigating the effect of the processing conditions on 
the crystalline morphology and mechanical properties of the resulting composites. Tensile, flexural, short beam shear and impact testing were employed to evaluate the carbon fiber/pCBT composites.

\section{Experimental}

\subsection{Materials}

In this study, CBT pellets (Grade: 160) purchased from Cyclics (Schenectady, NY; USA www.cyclics. com) were used. CBT was produced with an average molecular weight $M_{\mathrm{W}}=(220)_{\mathrm{n}}(n=2 \sim 7)$ for the purpose of engineering plastic and composite applications. The CBT polymerizes within the presence of a butyl tin chloride dihydroxide catalyst (Fascat 4101 by Arkema) which is already added to the CBT resin by the manufacture. CBT was dried overnight in an $85^{\circ} \mathrm{C}$ vacuum oven and kept in a desiccator until further use. 3K carbon fiber (HTA40, Toho Tenax America, USA) in a twill weave was used as a reinforcement.

\subsection{Sample preparation}

This study used a modified film stacking technique [31] to produce high quality impregnated and void free carbon/pCBT composites. First, the CBT matrix was pressed in a compression mold into a $300 \mu \mathrm{m}$ thick film with $5 \mathrm{MPa}$ of pressure at $150^{\circ} \mathrm{C}$ for 1 min. Carbon/pCBT prepreg with an average thickness of 300 350 $\mu \mathrm{m}$ was prepared using the following procedure: A layer of carbon fabric was placed on a CBT thin film and pressed at $150^{\circ} \mathrm{C}$ under $8 \mathrm{MPa}$ of pressure for $3 \mathrm{~min}$, and then quenched to room temperature. In order to simplify the crystallization process of $\mathrm{pCBT}$, polymerization category of type III samples were polymerized at $230^{\circ} \mathrm{C}$ for $30 \mathrm{~min}$. to allow complete polymerization without crystallization. The carbon/pCBT composites were prepared by stacking eight layers of prepreg and pressed them at $230^{\circ} \mathrm{C}$ for 30 min under $12 \mathrm{MPa}$ of pressure to allow for complete polymerization. This was followed by quenching until the desired crystallization temperatures $\left(T_{\mathrm{c}}=185,195\right.$, and $\left.210^{\circ} \mathrm{C}\right)$ were reached. Based on crystallization kinetics studies [14], the time for complete crystallization is $20 \min$ for $T_{\mathrm{c}}=185^{\circ} \mathrm{C}, 40 \min$ for $T_{\mathrm{c}}=195^{\circ} \mathrm{C}$, and $120 \mathrm{~min}$ for $T_{\mathrm{c}}=210^{\circ} \mathrm{C}$. The composite samples were then slowly cooled to room temperature and removed from the mold. The fiber volume fractions of the carbon/pCBT composites were determined by burning test method according to ASTM D3171. The void fractions of the carbon/pCBT composites were determined according to ASTM D2734.The resulted fiber volume fraction and void fraction were $51.4 \pm 0.7$ and $0.4 \pm 0.2 \%$, respectively.

\subsection{Experimental methods}

\subsubsection{Molecular weight and polydispersity index}

Gel permeation chromatography (GPC) was used to determine the molecular weight, polydispersity index (PDI) and the conversion of the pCBT matrix. The GPC was performed on a modular system comprising a Waters 501 HPLC pump, a Waters 410 refractive index detector and a Waters column (Styragel ${ }^{\circledR} \mathrm{HR} 4 \mathrm{THF}$ ). The mobile phase was unstabilized $\mathrm{CHCl}_{3}$ at a flow rate of $1 \mathrm{~mL} / \mathrm{min}$ at $30^{\circ} \mathrm{C}$. In order to relate retention time to molecular weight, a universal calibration was made using narrow distribution polystyrene standards (Millipore Co., Massachusetts, USA). For sample preparation, approximately $4 \mathrm{mg}$ of matrix was dissolved in a mixture of chloroform/hexafluro-2-propanol (HFIP) (85/15 $\mathrm{CHCl}_{3} / \mathrm{HFIP}$ ). Samples containing carbon fibers were filtered before injection.

\subsubsection{Mechanical tests}

In this study, a universal testing machine (AG$100 \mathrm{kNX}$, Shimadzu, Japan) was used to perform the tensile, flexural and short beam shear (SBS) tests at room temperature. Tensile tests were performed on the carbon/pCBT composites in accordance with the ASTM-D3039. Three-point bending and short beam shear (SBS) tests were carried out according to the ASTM D790 and D2344, respectively, to estimate the flexural and apparent interlaminar shear strength (ILSS). Tensile specimens cut from the prepared carbon/pCBT composite samples were $250 \times 25 \times 2 \mathrm{~mm}^{3}$ in normal dimension and were clamped over an area of $50 \times 25 \mathrm{~mm}^{2}$ at each end leaving a gauge length of $150 \mathrm{~mm}$. Aluminum tabs were glued onto the ends of specimen to aid gripping areas. The grip pressure was hydraulically controlled. The testing cross-head speeds were $5 \mathrm{~mm} / \mathrm{min}$ for the tensile test. The axial displacement was measured by the machine according to the movement of the crosshead. Three-point bending test was conducted to evaluate the flexural properties of the carbon/pCBT composites. Specimens in $138 \mathrm{~mm}$ long and $25.4 \mathrm{~mm}$ wide by $3.6 \mathrm{~mm}$ thick 
were cut from the carbon/pCBT composite plates. A span length of $115 \mathrm{~mm}$ assured a span-to-depth ratio of 32, and a crosshead speed of $3.4 \mathrm{~mm} / \mathrm{min}$ was adopted. A $22.8 \times 6 \times 3.6 \mathrm{~mm}^{3}$ SBS specimen was placed on two cylindrical supports, each $2 \mathrm{~mm}$ in diameter, and bent in the middle by a cylindrical head $6 \mathrm{~mm}$ in diameter. The crosshead had a rate of $1 \mathrm{~mm} / \mathrm{min}$ and there was a span-to-thickness ratio of 4.

The Izod impact test was performed at room temperature according to ASTM D256 on a pendulum impact tester (CPI, Atlas electric devices, USA) at impact energy of $2.54 \mathrm{~J}$. The impact velocity used was $3.4 \mathrm{~m} / \mathrm{sec}$. The dimensions for the Izod impact specimen were $63.5 \times 12.7 \times 3.6 \mathrm{~mm}^{3}$, and were provided with a $2.7 \pm .2 \mathrm{~mm}$ deep notch. The notches in the samples were opened by using a notch opener (QC-640, Cometech testing machines, Taiwan), and were all with a notch tip radius of $0.25 \mathrm{~mm}$. All the mechanical properties reported represent the average value of five readings at least. To investigate the effects of reinforcement on the carbon/pCBT composite failure modes, the failure and cross-sectional area of the damaged samples were examined using an optical microscope and SEM.

\subsubsection{Morphology observation of the carbon/pCBT composites}

The morphology of carbon/pCBT composites was examined under a polarized light microscope (PLM) equipped with a Linkam THMS 600 hot stage (Linkam, Epsom, UK). A quartz plate was used to determine the sign of the pCBT spherulite's birefringence. In this way, the first and third quarters of the sight were yellow and the second and fourth were blue when the forms were negative, while a reversed arrangement of the quarters was observed for positive forms. A small piece of CBT enclosed by high tenacity carbon fibers was pressed between two microscope slides and then inserted into the hot stage. Nitrogen was used as the purge gas in the hot stage during all measurements and thermal treatments. Each sample was heated to $230^{\circ} \mathrm{C}$ at a rate of $130^{\circ} \mathrm{C} / \mathrm{min}$, held for $30 \mathrm{~min}$ to allow for complete polymerization, and then cooled to the desired $T_{\mathrm{c}}$ at a rate of $60^{\circ} \mathrm{C} / \mathrm{min}$, where $T_{\mathrm{c}}=185,195$ and $210^{\circ} \mathrm{C}$.

\subsubsection{Degree of crystallinity}

The crystallinity of pCBT matrix were examined by DSC (TA-Du Pont DSC Q10 series) calibrated with indium at heating rate of $50^{\circ} \mathrm{C} / \mathrm{min}$. In order to suppress the reorganization and to avoid the superheating of high crystallinity specimens, which may influence the determination of crystallinity, higher heating rate of $50^{\circ} \mathrm{C} / \mathrm{min}$ was used. Experiments were run with samples ranging from $3 \sim 5 \mathrm{mg}$ under nitrogen to prevent moisture and oxidative degradation. The crystallized matrix was heated from RT to $280^{\circ} \mathrm{C}$ at the rate of $50^{\circ} \mathrm{C} / \mathrm{min}$. The heat of fusion was determined from the areas under the melting peak. Correction was made to account the presence of the carbon fibers. The fiber mass fraction of the composite samples was accurately determined by thermogravimetric analysis after DSC analysis and the measured melting enthalpy was renormalized to the actual amount of pCBT presence in the sample. The degree of crystallinity $\left(X_{\mathrm{c}}\right)$ of the pCBT samples was calculated from Equation (1):

$X_{\mathrm{c}}=\frac{\Delta H}{\left(1-M_{\mathrm{f}}\right) H_{\mathrm{f}}}$

where $M_{\mathrm{f}}$ mass fraction of reinforcement, $H_{\mathrm{f}}$ heat of fusion of the fully perfect crystal of PBT with a value of $142 \mathrm{~J} / \mathrm{g}[14,15], \Delta H$ absolute value of the heat of crystallization or fusion, measured as the area underneath the peaks.

\section{Results and discussion}

\subsection{Results of the GPC measurements and crystallinity of the carbon/pCBT composites}

Molecular weight is having an effect on processing, crystallization and mechanical properties of the crystalline polymer. Crystalline polymers have an additional strengthening mechanism resulting from their crystalline structure and as the chains become long, molecular entanglements and intermolecular forces become so great that the chains no longer slip over each other. However, segregation of low molecular weight oligomer at the spherulitic boundaries causes the weak boundary regions between spherulites. It is also having a detrimental effect on the mechanical properties of material [32]. Table 1 
Table 1. Results of the GPC measurements and crystallinity on the carbon/pCBT composites at different $T_{\mathrm{c}}$

\begin{tabular}{|l|c|c|c|}
\hline \multicolumn{1}{|c|}{$\mathbf{T}_{\mathbf{c}}$} & $\mathbf{1 8 5}^{\circ} \mathbf{C}$ & $\mathbf{1 9 5}^{\circ} \mathbf{C}$ & $\mathbf{2 1 0}^{\circ} \mathbf{C}$ \\
\hline$M_{\mathrm{w}}[\mathrm{kg} / \mathrm{mol}]$ & 110 & 103 & 111 \\
\hline$M_{\mathrm{n}}[\mathrm{kg} / \mathrm{mol}]$ & 42 & 45 & 51 \\
\hline$M_{\mathrm{w}} / M_{\mathrm{n}}[\mathrm{PDI}]$ & 2.61 & 2.27 & 2.19 \\
\hline Conversion [\%] & 99.5 & 99.5 & 99.9 \\
\hline Crystallinity [\%] & 34 & 38 & 45 \\
\hline
\end{tabular}

shows molecular weights, polydispersity index and the conversion of the $\mathrm{pCBT}$ matrixes measured by GPC. The number average molecular weight (Mn) for pCBT samples at $T_{\mathrm{c}}=210^{\circ} \mathrm{C}$ was $51 \mathrm{~kg} / \mathrm{mol}$, whereas that for $\mathrm{pCBT}$ samples at $T_{\mathrm{c}}=185$ and $195^{\circ} \mathrm{C}$ ranged from $42 \sim 45 \mathrm{~kg} / \mathrm{mol}$. The percentages of conversion for all the pCBT samples were very high with value above $99.5 \%$. As the crystallization temperature increases, the PDI decreased from 2.61 at $185^{\circ} \mathrm{C}$ to 2.19 at $210^{\circ} \mathrm{C}$ along with an increase in molecular weight. The results suggested that a low molecular weight tail was observed in the GPC traces and became obviously for the pCBT samples at lower $T_{\mathrm{c}}$.

Figure 1 shows the DSC melting curves of carbon/ pCBT composites prepared at different $T_{\mathrm{c}}$. Double melting peaks appeared for carbon/pCBT samples at $T_{\mathrm{c}}=185$ and $195^{\circ} \mathrm{C}$ respectively. The crystallinity of the carbon/pCBT composites at different $T_{\mathrm{c}}$ were calculated and summarized in Table 1. All of the

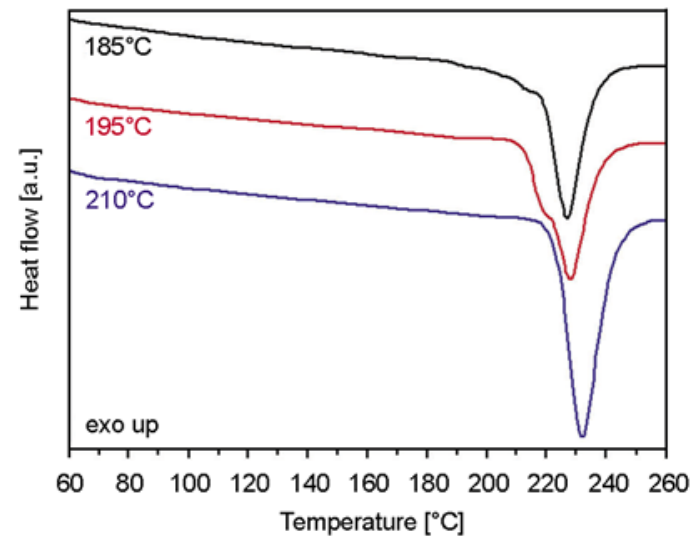

Figure 1. DSC melting thermograms of carbon/pCBT composites at different $T_{\mathrm{c}}$

composites' crystallinity increased with rise in $T_{\mathrm{c}}$. The carbon/pCBT sample that crystallized at $210^{\circ} \mathrm{C}$ exhibits the highest crystallinity: $45 \%$, whereas samples at $T_{\mathrm{c}}=185$ and $195^{\circ} \mathrm{C}$ were 34 and $38 \%$ respectively.

\subsection{The morphology of the carbon/pCBT composites}

Figure 2 shows PLM images of the pCBT's crystalline morphologies during and complete crystallization at different $T_{\mathrm{c}}$. The samples prepared at $T_{\mathrm{c}}=$ 185 and $195^{\circ} \mathrm{C}$ revealed unusual and mixed birefringence spherulite morphologies during crystallization. The spherulite size was larger in the sam-

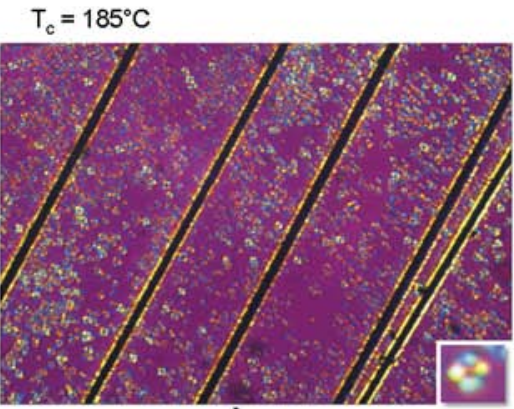

a)

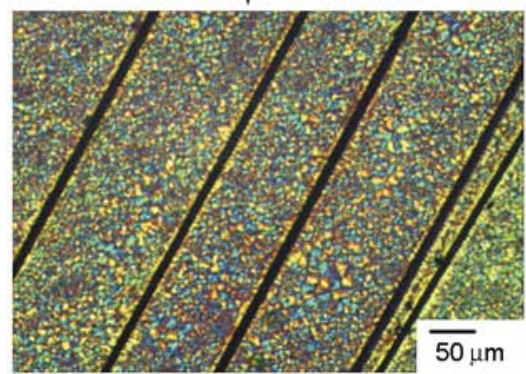

d)

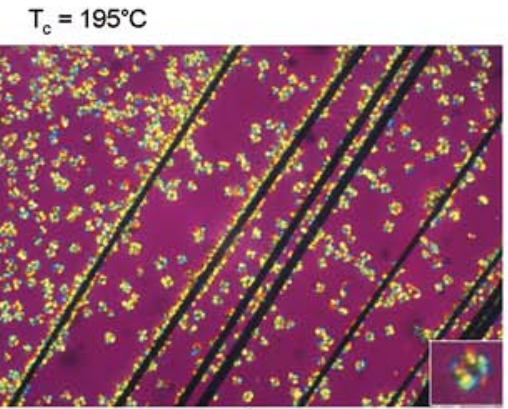

b)

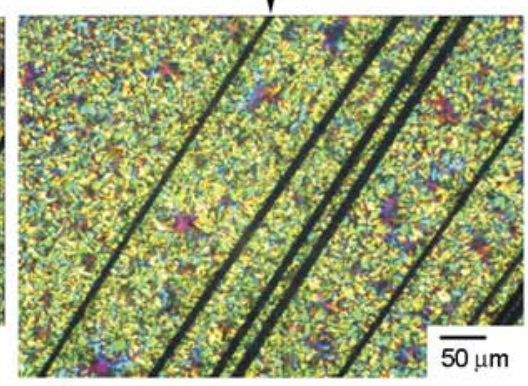

e)

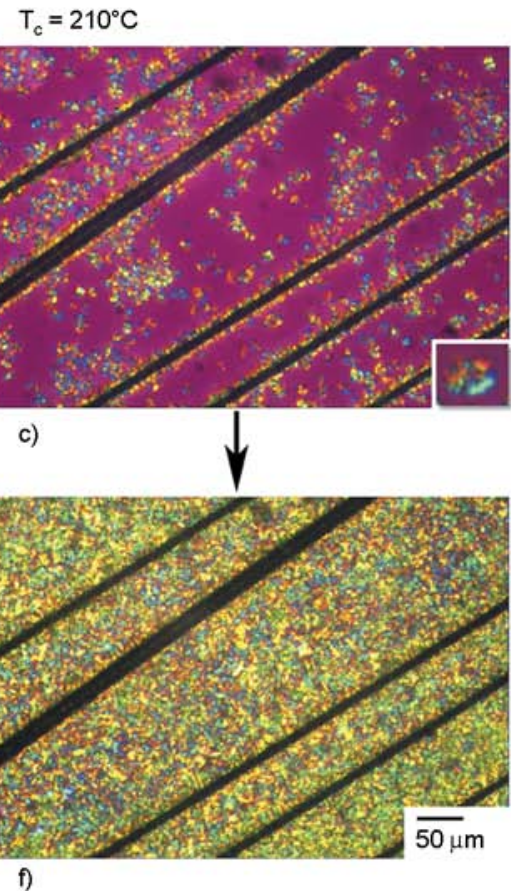

Figure 2. Crystalline morphologies of the carbon/pCBT composites during crystallization at different $T_{\mathrm{c}}$ : (a) $185^{\circ} \mathrm{C}$, (b) $195^{\circ} \mathrm{C}$, (c) $210^{\circ} \mathrm{C}$ and complete crystallization at different $T_{\mathrm{c}}$ : (d) $185^{\circ} \mathrm{C}$, (e) $195^{\circ} \mathrm{C}$, (f) $210^{\circ} \mathrm{C}$ 
ple prepared at $T_{\mathrm{c}}=195^{\circ} \mathrm{C}$ than that of $T_{\mathrm{c}}=185^{\circ} \mathrm{C}$. Interestingly, boundary crystals and spherulitic boundary lines were found in the samples prepared at $T_{\mathrm{c}}=185$ and $195^{\circ} \mathrm{C}$. The boundary crystals are attributed to the crystallization of low molecular weight pCBT molecules. The boundary region becomes a weak point of the material due to the segregation of low molecular weight oligomer at the spherulitic boundaries. The spherulitic boundary line became unclear gradually as the crystallization temperature increased. Worthy of notice is that the spherulitic boundary lines and the boundary crystals vanished in the samples prepared at $T_{\mathrm{c}}=210^{\circ} \mathrm{C}$. As for the samples at $T_{\mathrm{c}}=210^{\circ} \mathrm{C}$, the spherulite morphology was lost and highly disordered spherulitic crystallites were observed. In general, there is no work yet found to achieve less segregation boundary defects in highly crystalline material with large number of spherulites The implication is that the potential strength of the highly crystalline material is large but the problem is to obtain good boundary cohesion. However, pCBT sample prepared at $T_{\mathrm{c}}=$ $210^{\circ} \mathrm{C}$ provides an opportunity to produce a polymer with high crystallinity, and less segregation boundary defects. It is believed that pCBT sample with high crystallinity and less boundary defects can provide good mechanical properties [25] and will be discussed later.

In all three conditions, the transcrystalline phenomenon was clearly observed (Figure 2). In contrast to samples from $T_{\mathrm{c}}=185$ and $195^{\circ} \mathrm{C}$, a well-defined transcrystalline structure was revealed when the pCBT crystallized at $210^{\circ} \mathrm{C}$. This is the first time that a well-defined transcrystalline structure was clearly observed in a pCBT polymer under quiescent crystallization conditions. Owing to the mutual interaction between the fiber and pCBT matrix, it can be assumed that the interfacial properties are excellent. Transcrystallization of pCBT can be attributed to heterogeneous nucleation induced by carbon fiber. However, as shown in Figure 2, spherulites abounded in the pCBT matrix and not affected by the crystallization temperature. This finding implies that the nucleation rate of $\mathrm{pCBT}$ resin shall be quite high and cause the difficulty on determining spherulitic growth rate and kinetics analysis [14]. It is noteworthy that all transcrystalline morphology might occur in the carbon/pCBT composites due to higher fiber volume fraction. The transcrystalline boundary region (boundary crystal and boundary line) still can be formed in between the two growing transcrystals. Hence, the concept of weak boundaries is meaningful to explain the mechanical response of carbon/pCBT composites.

\subsection{Effects of $T_{c}$ on the mechanical properties of carbon/pCBT composites}

Figure 3 shows the typical tensile stress-strain curves of the carbon/pCBT composites at different $T_{\mathrm{c}}$. All the three samples demonstrate a severely vibrating curve before the final catastrophic fracture. The major failure modes, as shown in Figure 4, are longrange delamination (Figure 4a), and multifilament bundle shear breakage (Figure 4b). Due to the twill weave, stress concentrated on the fiber bundles around the interlace points and lead to their shear breakage. When the bundles split or experienced breakage, the released fracture energy dissipated through large amounts of long-range delamination, resulting in stress vibrations. Figure 5 displays the SEM micrographs of carbon/pCBT sample corroborates the good interfacial bonding between the constituent materials. All the carbon fiber bundles were coated with pCBT resins. Thus, the long-range delamination was due to cohesive failure of the pCBT matrix. Fine voids were developed at specimen's defects such as spherulite/transcrystalline boundaries and grown into the specimen. Failure along the spherulite/transcrystalline boundaries was promoted by decohesion between the spherulites due to the missing inter-spherulitic tie chains. Weak sites in the boundaries for $\mathrm{pCBT}$ composite sample at $T_{\mathrm{c}}=185^{\circ} \mathrm{C}$ was caused by segregation phenom-

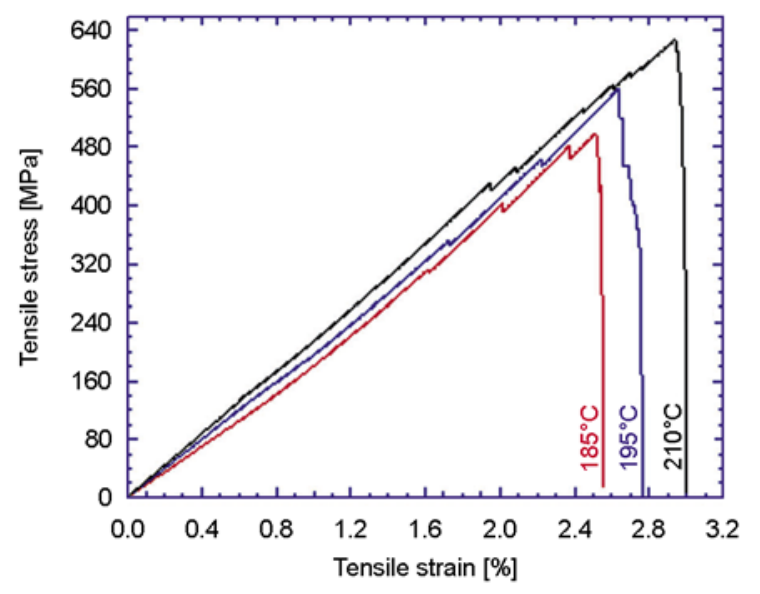

Figure 3. Typical tensile stress-strain curves of the carbon/pCBT composites at different $T_{\mathrm{c}}$ 


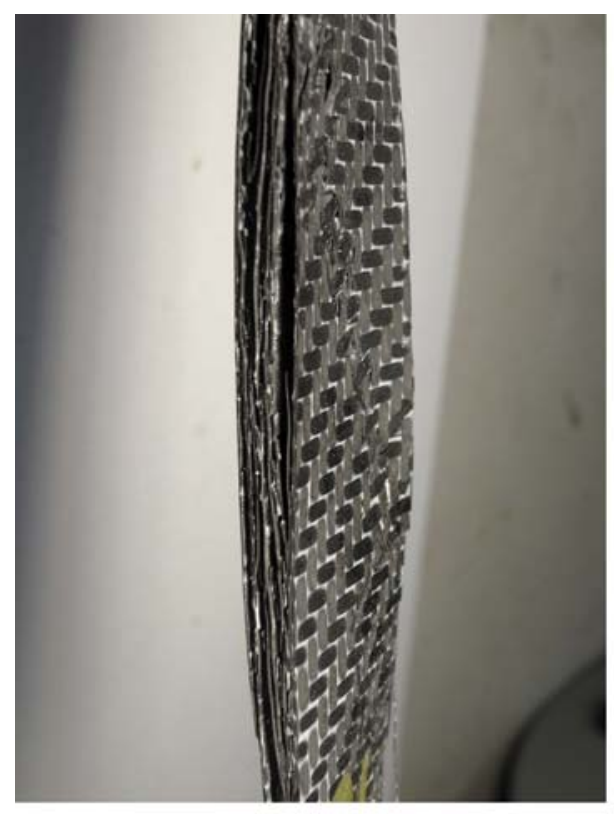

a)

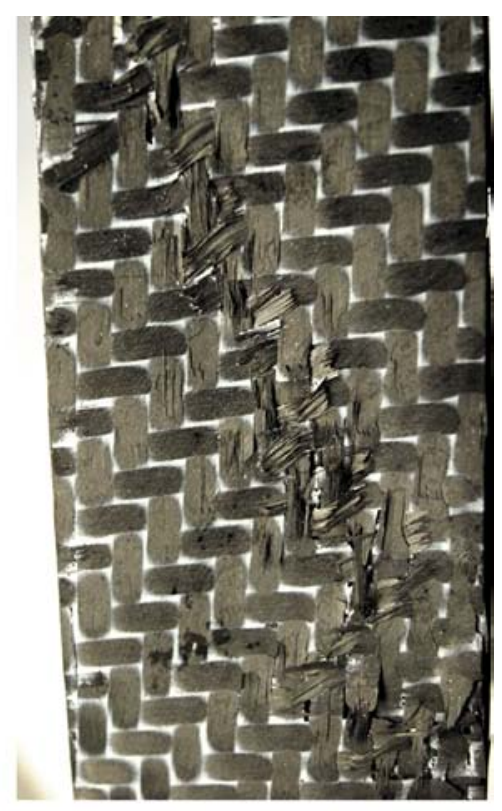

b)

Figure 4. Typical tensile failure modes for the carbon/pCBT composites. (a) lateral view: delamination failure, (b) front view: shear breakage of bundle filaments.

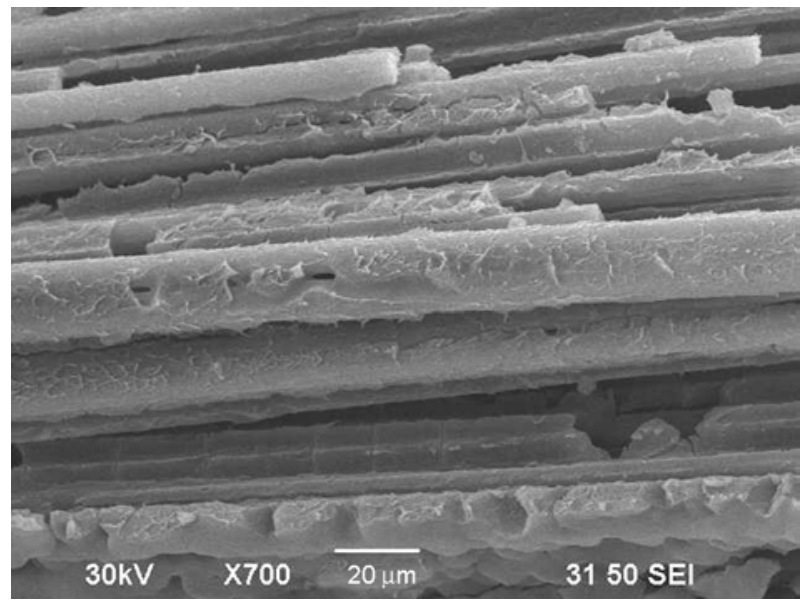

Figure 5. SEM image showing good interfacial fiber/matrix bonding and resulted in the cohesive failure for the carbon/pCBT composites

ena and enrichment of low molecular weight species (large PDI) being ejected from the crystallizing front.

Table 2 summarizes the tensile properties of carbon/pCBT composites with different $T_{\mathrm{c}}$. All of the composites' tensile properties increased with a rise in $T_{\mathrm{c}}$. The carbon/pCBT sample that crystallized at $210^{\circ} \mathrm{C}$ exhibited the highest tensile modulus: 22.2 GPa and greatest strength: $595 \mathrm{MPa}, 14$ and $17 \%$ greater, respectively, than those of the composite sample at $T_{\mathrm{c}}=185^{\circ} \mathrm{C}$. It is worthy to notice that the spherulite morphology of the $T_{\mathrm{c}}=210^{\circ} \mathrm{C}$ sample exhibited highly disordered crystallites with-
Table 2. Mechanical properties of the carbon/pCBT composites at different $T_{\mathrm{c}}$

\begin{tabular}{|l|c|c|c|}
\hline \multicolumn{1}{|c|}{$\mathbf{T}_{\mathbf{c}}$} & $\mathbf{1 8 5}^{\circ} \mathbf{C}$ & $\mathbf{1 9 5}^{\circ} \mathbf{C}$ & $\mathbf{2 1 0}^{\circ} \mathbf{C}$ \\
\hline Tensile modulus [GPa] & $19.4 \pm 1.8$ & $20.5 \pm 1.4$ & $22.2 \pm 1.3$ \\
\hline Tensile strength [MPa] & $510 \pm 13$ & $546 \pm 29$ & $595 \pm 32$ \\
\hline Tensile elongation [\%] & $2.35 \pm 0.38$ & $2.55 \pm 0.15$ & $2.86 \pm 0.21$ \\
\hline Flexural modulus [GPa] & $43.6 \pm 2.4$ & $42.4 \pm 1.0$ & $45.1 \pm 3.3$ \\
\hline Flexural strength [MPa] & $403 \pm 8$ & $407 \pm 9$ & $508 \pm 13$ \\
\hline Impact energy [J/m] & $779 \pm 4$ & $774 \pm 8$ & $809 \pm 8$ \\
\hline ILSS [MPa] & $54.1 \pm 1.2$ & $55.2 \pm 1.0$ & $59.7 \pm 0.4$ \\
\hline
\end{tabular}

out clear spherulitic boundaries or boundary crystals. This matrix behaved like a homogeneous material without phase separation. Morphology that contained clear boundaries and boundary crystals (defects) had a negative effect that caused a decrease in tensile performance.

Figure 6 shows the typical flexural stress-strain curves of the carbon/pCBT composites at different $T_{\mathrm{c}}$. Flexural properties such as flexural modulus and strength were summarized in Table 2 . Similarly to the tensile results; all the curves exhibited a severe vibration at flexural strain larger than $1 \%$. This stress vibration is relative to the fiber bundle breakage and short-range delamination. Failure modes: compressive, tensile failures and shear delamination, are seen in Figure 7a. The failure on the tension surface involved fiber bundle breakage, cracks and short range delamination (Figure 7b). The compression surface failure included local buckling 


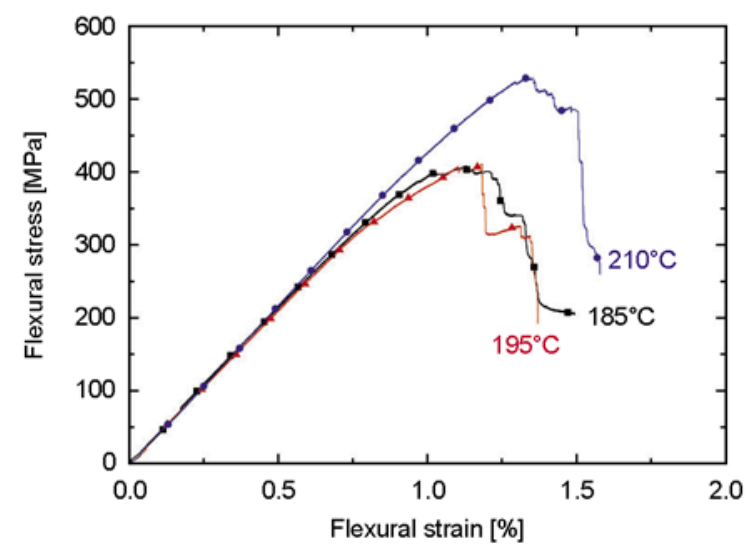

Figure 6. Typical flexural stress-strain curves of the carbon/pCBT composites at different $T_{\mathrm{c}}$

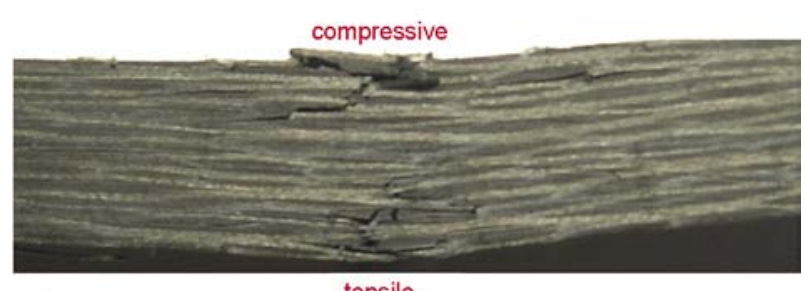

a)

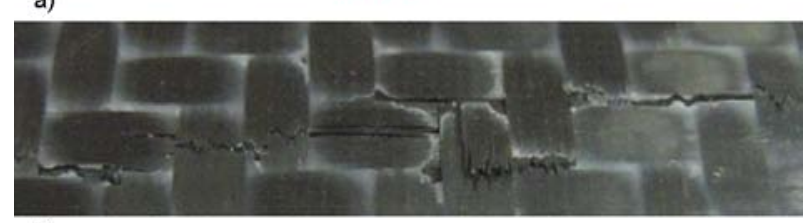

b)

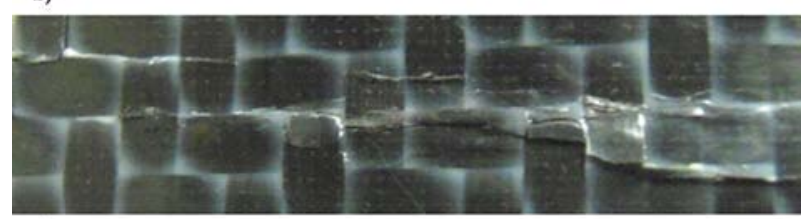

c)

Figure 7. Typical flexural failure for the carbon/pCBT composites, (a) lateral view, (b) tensile surface, (c) compression surface

which manifested as fiber micro-buckling and plylevel buckling (Figure 7c). The ply-level buckling caused short range delamination of the outer ply. All of the samples, however, did not collapse directly under flexural loading. This demonstrates that the reinforcement of the carbon fabric prevents crack propagation.

Also similar to the tensile results, the composite sample at $T_{\mathrm{c}}=210^{\circ} \mathrm{C}$ exhibited the highest flexural modulus: $45.1 \mathrm{GPa}$ (as shown in Table 2), which is attributed to a higher degree of crystallinity (44\%). The flexural strength of the composite sample at $T_{\mathrm{c}}=$ $210^{\circ} \mathrm{C}$ was $508 \mathrm{MPa}$, whereas samples at $T_{\mathrm{c}}=185$ and $195^{\circ} \mathrm{C}$ were $403 \sim 407 \mathrm{MPa}$, with $26 \%$ enhancement. These results demonstrate that crystalline mor- phology strongly influenced the mechanical properties of the carbon/pCBT composites. Sample morphology without spherulitic boundaries prevents the crack initiation and growth. In addition, pCBT samples with high crystallinity promote the resistance of crack propagation. Hence, composite samples at $T_{\mathrm{c}}=210^{\circ} \mathrm{C}$ containing highly disordered crystallites without spherulitic boundaries or boundary crystals displayed the best tensile and flexural property results.

The notched Izod impact properties of the composites are shown in Table 2. The impact energy for composite samples at $T_{\mathrm{c}}=210^{\circ} \mathrm{C}$ was $809 \mathrm{~J} / \mathrm{m}$, whereas for samples at $T_{\mathrm{c}}=185$ and $195^{\circ} \mathrm{C}$ ranged from 774 779 MPa and had 5\% enhancement. The failure modes for impacted carbon/pCBT composites had tensile and compressive failure, but did not break apart (Figure 8a). This impact failure reveals the preventive ability of the reinforcing woven fabric against cracking. When the impactor encountered the carbon/pCBT specimen, fiber bundle pullout and breakage occurred around the notched side of the composite, while compressive force built up on the other side and caused crush of fibers and matrixes (Figure 8b). Figure 8c shows typical impact failure included fiber bundle crush and kink fracture, short range delamination in the compressive side of pCBT composites. A close view of the impacted carbon/pCBT composite in the tensile side, shown in Figure 9, reveals that all the pull-out fiber bundles were coated with pCBT resin. These results demonstrate that there is strong interfacial bonding between the carbon fiber and pCBT. The cohesive failure that occurred in the pCBT matrix was attributed to the brittleness of the $\mathrm{pCBT}$ resin.

The ILSS is a non-fiber dominated property that is influenced by both the matrix and interfacial properties. When the composite sample was subjected to loading, cracks normal to the loading direction formed either at the matrix/fiber interface or in the matrix. A low ILSS is therefore an indication of poor fiber/matrix interfacial properties or matrix brittleness.

There were no visible failures found during the ILSS testing of the pCBT composite samples. Failures may be preceded by less obvious, local damage, such as transply cracking. Figure 10 shows the typical load-displacement curves of the carbon/ pCBT composites at different $T_{\mathrm{c}}$. The interlaminar 


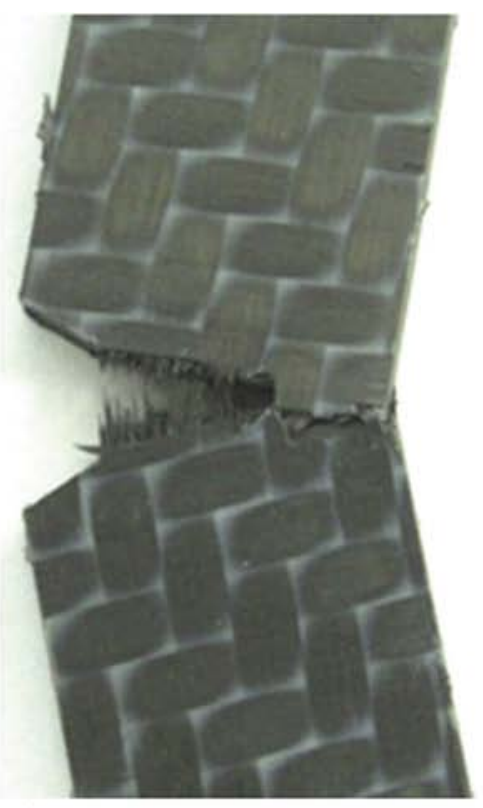

a)

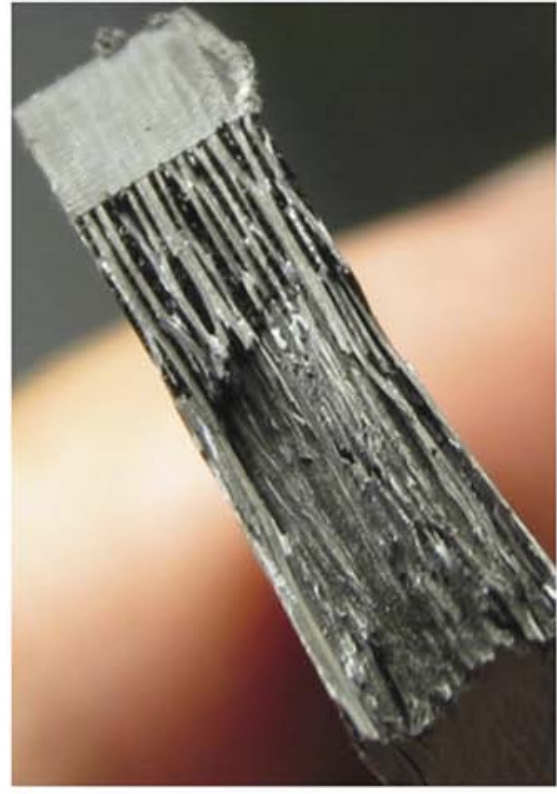

b)

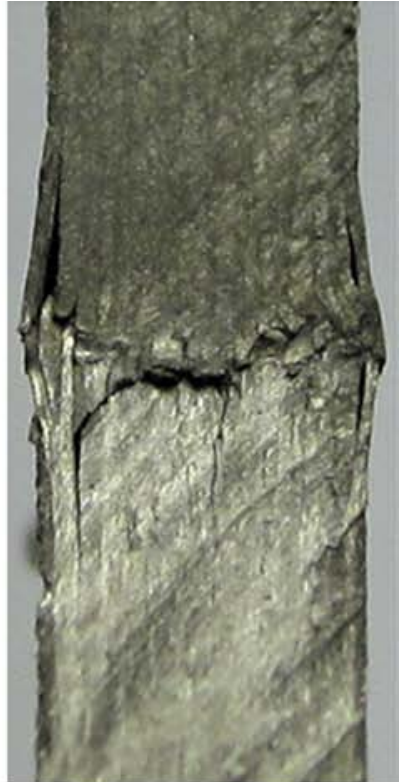

Figure 8. Typical impact failure modes for the carbon/pCBT composites: (a) lateral view, (b) top view, (c) compressive side

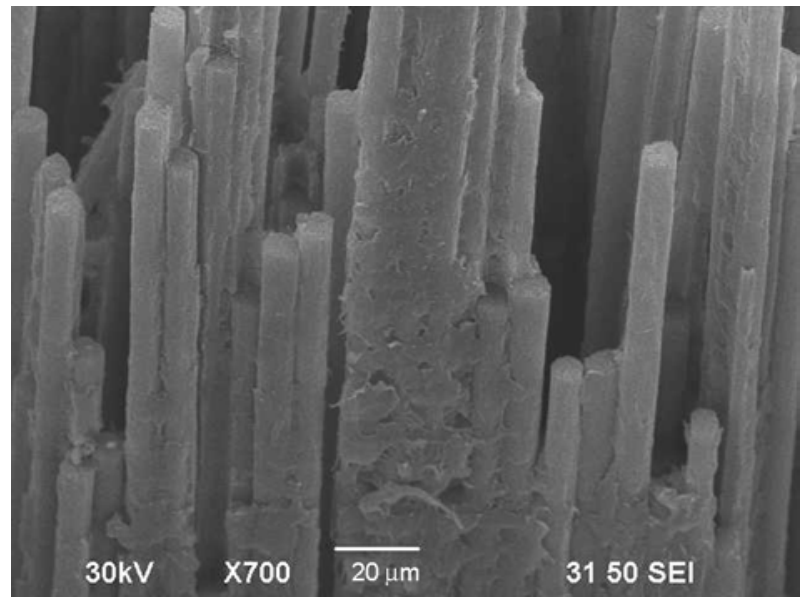

Figure 9. SEM images for the impact failure carbon/pCBT composites at tensile side showing cohesive failure at the fiber/matrix interphase

shear strength (ILSS) for carbon/pCBT composites was determined from the load-displacement curves and listed in Table 2. As shown in Table 2, for the sample of $T_{\mathrm{c}}=210^{\circ} \mathrm{C}$ displayed the highest ILSS: 59.7 $\mathrm{MPa}$, which was much higher than those obtained from the glass/pCBT composites (34.3 MPa) [16]. Remember that the transcrystalline morphology and cohesive failure were found in all the carbon/pCBT composite samples. Slight variation in the ILSS (54 59 MPa) revealed the effects of transcrystalline and crystallinity on the interfacial adhesion.

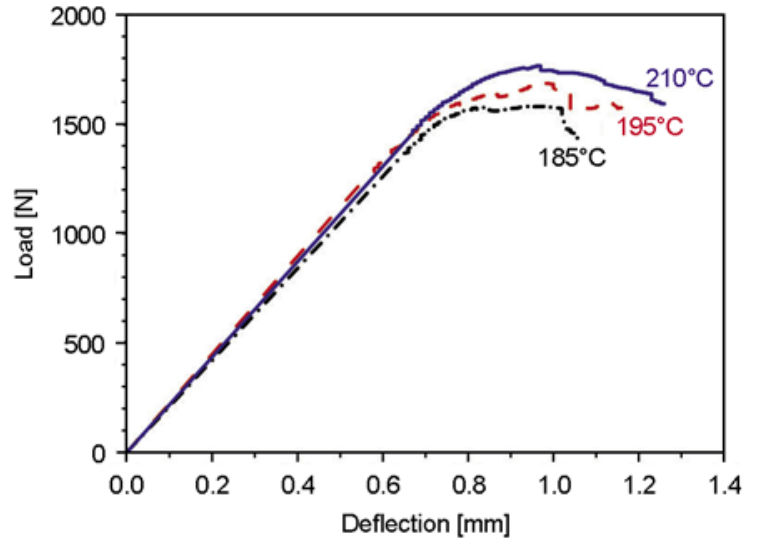

Figure 10. Typical load-displacement curves of short beam shear test for the carbon/pCBT composites at different $T_{\mathrm{c}}$

\section{Conclusions}

In this study, carbon/pCBT composites were prepared by a modified film stacking technique. Results demonstrated that their mechanical properties were strongly affected by crystalline morphologies and crystallinity. A well-defined transcrystallinity can be clearly seen in carbon/pCBT composites in quiescent crystallization conditions. The low crystallinity of the carbon/pCBT composites sample crystallized at $185^{\circ} \mathrm{C}$ with spherulitic structure led to large area spherulite/transcrystalline boundary region. Consequently, the crack tended to initiate and propagate along the 'weak' spherulite/ 
transcrystalline boundaries, resulting in a low value of mechanical properties. The carbon/pCBT composite sample prepared at $T_{\mathrm{c}}=210^{\circ} \mathrm{C}$ and displaying highly disordered spherulitic crystallites without spherulite/transcrystalline boundary lines or boundary crystals exhibited the best mechanical properties.

\section{Acknowledgements}

Part of this work is financially supported from the National Science Council of Taiwan, ROC, under contract number NSC 98-2221-E-035-001.

\section{References}

[1] Brunelle D. J.: Cyclic oligomer chemistry. Journal of Polymer Science Part A: Polymer Chemistry, 46, 11511164 (2008). DOI: $10.1002 /$ pola.22526

[2] Brunelle D. J., Bradt J. E., Serth-Guzzo J., Takekoshi T., Evans T. L., Pearce E. J., Wilson P. R.: Semicrystalline polymers via ring-opening polymerization: Preparation and polymerization of alkylene phthalate cyclic oligomers. Macromolecules, 31, 4782-4790 (1998).

DOI: $10.1021 / \mathrm{ma971491 \textrm {j }}$

[3] Parton H., Verpoest I.: In situ polymerization of thermoplastic composites based on cyclic oligomers. Polymer Composites, 26, 60-65 (2005).

DOI: $10.1002 /$ pc. 20074

[4] Mohd Ishak Z. A., Gatos K. G., Karger-Kocsis J.: On the in-situ polymerization of cyclic butylene terephthalate oligomers: DSC and rheological studies. Polymer Engineering and Science, 46, 743-750 (2006). DOI: 10.1002/pen.20486

[5] Mohd Ishak Z. A., Shang P. P., Karger-Kocsis J.: A modulated DSC study on the in situ polymerization of cyclic butylene terephthalate oligomers. Journal of Thermal Analysis and Calorimetry, 84, 637-641 (2006). DOI: 10.1007/s10973-005-7059-Z

[6] Harsch M., Karger-Kocsis J., Apostolov A. A.: Crystallization-induced shrinkage, crystalline, and thermomechanical properties of in situ polymerized cyclic butylene terephthalate. Journal of Applied Polymer Science, 108, 1455-1461 (2008).

DOI: $10.1002 / \mathrm{app} .27798$

[7] Lehmann B., Karger-Kocsis J.: Isothermal and nonisothermal crystallisation kinetics of pCBT and PBT: Polymers as studied by DSC. Journal of Thermal Analysis and Calorimetry, 95, 221-227 (2009). DOI: $10.1007 / \mathrm{s} 10973-007-8939-1$

[8] Karger-Kocsis J., Shang P. P., Mohd Ishak Z. A., Rösch M.: Melting and crystallization of in-situ polymerized cyclic butylene terephthalates with and without organoclay: A modulated DSC study. Express Polymer Letters, 1, 60-68 (2007).

DOI: $10.3144 /$ expresspolymlett.2007.12
[9] Lanciano G., Greco A., Maffezzoli A., Mascia L.: Effects of thermal history in the ring opening polymerization of CBT and its mixtures with montmorillonite on the crystallization of the resulting poly(butylene terephthalate). Thermochimica Acta, 493, 61-67 (2009). DOI: $10.1016 /$ j.tca.2009.04.004

[10] Tripathy A. R., Elmoumni A., Winter H. H., MacKnight W. J.: Effects of catalyst and polymerization temperature on the in-situ polymerization of cyclic poly(butylene terephthalate) oligomers for composite applications. Macromolecules, 38, 709-715 (2005). DOI: $10.1021 / \mathrm{ma} 0483874$

[11] Hakmé C., Stevenson I., Maazouz A., Cassagnau P., Boiteux G., Seytre G.: In situ monitoring of cyclic butylene terephtalate polymerization by dielectric sensing. Journal of Non-Crystalline Solids, 353, 43624365 (2007). DOI: $10.1016 /$ j.jnoncrysol.2007.04.051

[12] Parton H., Baets J., Lipnik P., Goderis B., Devaux J., Verpoest I.: Properties of poly(butylene terephthalate) polymerized from cyclic oligomers and its composites. Polymer, 46, 9871-9880 (2005).

DOI: $10.1016 /$ j.polymer.2005.07.082

[13] Parton H.: Characterization of the in-situ polymerization production process for continuous fiber reinforced thermoplastics. PhD thesis, Department of Metallurgy and Materials Science Katholieke Universiteit Leuven, Belgium (2006).

[14] Wu C-M., Jiang C-W.: Crystallization and morphology of polymerized cyclic butylene terephthalate. Journal of Polymer Science Part B: Polymer Physics, 48, 1124-1134 (2010). DOI: $10.1002 /$ polb.21998

[15] Wu C-M., Huang C-W.: Melting and crystallization behavior of copolymer from cyclic butylene terephthalate and polycaprolactone. Polymer Engineering and Science, 51, 1004-1013 (2011).

DOI: $10.1002 /$ pen. 21910

[16] Mohd Ishak Z. A., Leong Y. W., Steeg M., KargerKocsis J.: Mechanical properties of woven glass fabric reinforced in situ polymerized poly(butylene terephthalate) composites. Composites Science and Technology, 67, 390-398 (2007).

DOI: 10.1016/j.compscitech.2006.09.012

[17] Tripathy A. R., MacKnight W. J., Kukureka S. N.: Insitu copolymerization of cyclic poly(butylene terephthalate) oligomers and $\varepsilon$-caprolactone. Macromolecules, 37, 6793-6800 (2004).

DOI: $10.1021 / \mathrm{ma} 0400517$

[18] Baets J., Dutoit M., Devaux J., Verpoest I.: Toughening of glass fiber reinforced composites with a cyclic butylene terephthalate matrix by addition of polycaprolactone. Composites Part A: Applied Science and Manufacturing, 39, 13-18 (2008).

DOI: $\underline{10.1016 / \text { j.compositesa.2007.09.013 }}$ 
[19] Tripathy A. R., Chen W., Kukureka S. N., MacKnight W. J.: Novel poly(butylene terephthalate)/poly(vinyl butyral) blends prepared by in situ polymerization of cyclic poly(butylene terephthalate) oligomers. Polymer, 44, 1835-1842 (2003).

DOI: $10.1016 / \mathrm{S} 0032-3861(03) 00029-6$

[20] Jiang Z., Siengchin S., Zhou L-M., Steeg M., KargerKocsis J., Man H. C.: Poly (butylene terephthalate)/silica nanocomposites prepared from cyclic butylene terephthalate. Composites Part A: Applied Science and Manufacturing, 40, 273-278 (2009).

DOI: $10.1016 /$ j.compositesa.2008.12.003

[21] Baets J., Godara A., Devaux J., Verpoest I.: Toughening of polymerized cyclic butylene terephthalate with carbon nanotubes for use in composites. Composites Part A: Applied Science and Manufacturing, 39, 17561761 (2008).

DOI: 10.1016/j.compositesa.2008.08.004

[22] Wu F., Yang G.: Synthesis and properties of poly(butylene terephthalate)/multiwalled carbon nanotube nanocomposites prepared by in situ polymerization and in situ compatibilization. Journal of Applied Polymer Science, 118, 2929-2938 (2010).

DOI: $10.1002 / a p p .32625$

[23] Romhány G., Vígh J., Thomann R., Karger-Kocsis J., Sajó I. E.: pCBT/MWCNT nanocomposites prepared by in situ polymerization of CBT after solid-phase high-energy ball milling of CBT with MWCNT. Macromolecular Materials and Engineering, 296, 544-550 (2011).

DOI: $10.1002 /$ mame.201000381

[24] Baets J., Godara A., Devaux J., Verpoest I.: Toughening of isothermally polymerized cyclic butylene terephthalate for use in composites. Polymer Degradation and Stability, 95, 346-352 (2010). DOI: $10.1016 /$ j.polymdegradstab.2009.11.005

[25] Mäder E., Gao S-L., Plonka R., Wang J.: Investigation on adhesion, interphases, and failure behaviour of cyclic butylene terephthalate $\left(\mathrm{CBT}^{\circledR}\right) /$ glass fiber composites. Composites Science and Technology, 67, 3140-3150 (2007).

DOI: $10.1016 /$ j.compscitech.2007.04.014
[26] Shahzad M. A., Steeg M., Mitschang P.: Development and characterization of glass fiber reinforced in-situ polymerized thermoplastic matrix composite material. in 'SAMPE 2010, Seattle Canada' p15 (2010).

[27] Baets J., Devaux J., Verpoest I.: Toughening of basalt fiber-reinforced composites with a cyclic butylene terephthalate matrix by a nonisothermal production method. Advances in Polymer Technology, 29, 70-79 (2010).

DOI: $10.1002 / \mathrm{adv} .20176$

[28] Balogh G., Czigany T.: Effect of low UD carbon fibre content on mechanical properties of in situ polymerised cyclic butylene terephthalate. Plastics, Rubber and Composites, 40, 121-124 (2011) .

DOI: $10.1179 / 1743289811 X 12988633927871$

[29] Aurrekoetxea J., Zurbitu J., Ortiz de Mendibil I., Agirregomezkorta A., Sánchez-Soto M., Sarrionandia M.: Effect of superelastic shape memory alloy wires on the impact behavior of carbon fiber reinforced in situ polymerized poly(butylene terephthalate) composites. Materials Letters, 65, 863-865 (2011).

DOI: $10.1016 /$ j.matlet.2010.12.020

[30] López-Arraiza A., Amenabar I., Agirregomezkorta A., Agirregomezkorta, Aurrekoetzea J.: Experimental analysis of drilling damage in carbon-fiber reinforced thermoplastic laminates manufactured by resin transfer moulding. Journal of Composite Materials, in press (2011). DOI: $10.1177 / 0021998311414218$

[31] Chen J. C., Wu C. M., Pu F. C., Chiu C. H.: Fabrication and mechanical properties of self-reinforced poly(ethylene terephthalate) composites. Express Polymer Letters, 5, 228-237 (2011).

DOI: 10.3144 /expresspolymlett.2011.22

[32] Karger-Kocsis J.: Microstructural aspects of fracture in polypropylene and in its filled, chopped fiber and fiber mat reinforced composites. in 'Polypropylene: Structure, blends and composites, Vol. I Structure and Morphology' (ed.: Karger-Kocsis J.) Chapman and Hall, London, 142-201 (1995). 